\title{
Understanding the mechanisms of lung mechanical stress
}

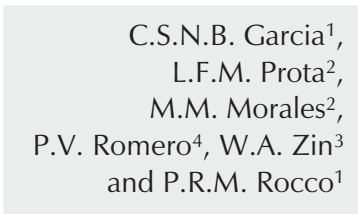

\author{
${ }^{1}$ Laboratório de Investigação Pulmonar, ${ }^{2}$ Laboratório de Fisiologia Molecular e Celular, \\ ${ }^{3}$ Laboratório de Fisiologia da Respiração, Instituto de Biofísica Carlos Chagas Filho, \\ Universidade Federal do Rio de Janeiro, Rio de Janeiro, RJ, Brasil \\ ${ }^{4}$ Laboratory of Experimental Pneumology, Ciutat Sanitaria de Bellvitge, IDIBELL, \\ Barcelona, Spain
}

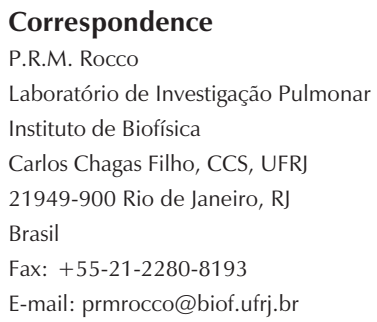

Received September 23, 2005 Accepted March 3, 2006

\begin{abstract}
Physical forces affect both the function and phenotype of cells in the lung. Bronchial, alveolar, and other parenchymal cells, as well as fibroblasts and macrophages, are normally subjected to a variety of passive and active mechanical forces associated with lung inflation and vascular perfusion as a result of the dynamic nature of lung function. These forces include changes in stress (force per unit area) or strain (any forced change in length in relation to the initial length) and shear stress (the stress component parallel to a given surface). The responses of cells to mechanical forces are the result of the cell's ability to sense and transduce these stimuli into intracellular signaling pathways able to communicate the information to its interior. This review will focus on the modulation of intracellular pathways by lung mechanical forces and the intercellular signaling. A better understanding of the mechanisms by which lung cells transduce physical forces into biochemical and biological signals is of key importance for identifying targets for the treatment and prevention of physical forcerelated disorders.
\end{abstract}

\section{Introduction}

Lung cells are normally subjected to a variety of mechanical forces as a result of the dynamic nature of lung function. Cells comprising the lung parenchyma, the airways, and the pulmonary and bronchial vascular systems are continuously subjected to a wide range of passive and active physical forces associated with lung inflation, vascular perfusion, and physical activity (1).

Over the past few years there has been increasing interest in mechanical stimulation and in its role in the regulation of cell structure, function, and metabolism (2). Cells

\section{Key words}

- Mechanical forces

- Mechanosensors

- Mechanotransduction

- Cell-cell interactions

- Cytokines

- Extracellular matrix subjected to strain or stress exhibit a diverse and extensive range of responses. Cell proliferation, differentiation, secretion, and movement, signal transduction, gene expression, and protein synthesis are events that could be modified by mechanical forces (2).

Abnormal physical forces exerted on lung tissues play a role in many pathological situations. However, how mechanical forces induce their deleterious effects needs to be clarified. In vitro studies have shown that both the pattern and the degree of stretch are important in determining the cellular response (3).

The mechanisms underlying the sensing 
and conversion of inappropriate mechanical stretch into cytotoxic and inflammatory mediators, and extracellular matrix (ECM) remodeling are beginning to be identified (4). In this review, we will focus on the modulation of intracellular pathways by mechanical forces. A better understanding of the key players at the cellular and molecular levels may identify targets for the treatment and prevention of physical force-related disorders.

\section{Characterization of mechanical stimuli}

Although physical forces are often designated by imprecise terms such as 'stretch' or 'distention', they are more accurately defined as follows: 'stress' (force per unit of area) or 'strain' (any forced change in length in relation to the initial length). When the forces are parallel to the plane, the stress is called 'shear stress'; when the stress is directed toward the part on which it acts it is called 'compressive stress', whereas when it is directed away from the part on which it acts it is called 'tensile stress'. Shear, compressive and tensile stresses respectively resist the tendency of the parts to slide, approach, or separate under the action of applied forces. A stretch is a 'tensile strain', a shortening is a 'compressive strain', and an angular distortion is a 'shear strain' (5).

Strain might be more prominent in cells of the alveolar epithelium during breathing, while shear stress may act mainly on the vascular endothelium (1). The endothelium might also be subjected to strain and hydrostatic pressure. Additionally, shear stress may act on other cells: pleural fluid affects pleural mesothelial cells and the fluid layer affects airway and alveolar epithelial cells (1). Finally, strain can be generated by cytoskeletal rearrangements such as actin contraction, leading to transmission of tension throughout the cell, including the nucleus (1).
In addition, the types of physical forces also differ depending on the part of the cell where they are acting. For example, fluid layer on airway and alveoli applies shear stress on the apical surface of epithelium, whereas the distension of the basement membrane applies stretch to the basolateral surface of the epithelial cells. These different types of physical forces applied to the same cell may activate different signal transduction pathways to mediate diverse biological functions.

\section{Putative mechanisms for mechanoreception and mechanotransduction}

Mechanotransduction is the conversion of mechanical stimuli into biochemical and biomolecular alterations. How mechanical forces can be sensed by cells (mechanosensors) and converted into biological and biochemical signals to cause changes in gene expression and cell metabolism is not well understood. The mechanosensor is defined as the system that detects the mechanical stimulus applied to the cell and converts it into a biological signal. Stretch-sensitive ion channels (6), and the ECM-integrin-cytoskeleton pathway (7) are the mechanosensing mechanisms that have received most attention. These mechanisms involve the activation and interplay of various intracellular events such as generation of second-messenger molecules, activation of specific protein kinases, phosphorylation and activation of participating signaling molecules, amplification through enzymatic cascades, and modulation of gene expression. In the nucleus, physical forces can exert their effects by influencing expression of immediate early response genes [c-fos, c-jun, c-myc, $J E$, ETS-like protein-1, activation protein-1 (AP-1), specificity protein-1, nuclear factor (NF)- $\kappa \mathrm{B}$, and early growth response-1], which encode proteins related to transcriptional factors and signal transduction (8). 
Transcriptional factors are DNA-binding proteins that regulate gene expression. Among these, NF- $\kappa \mathrm{B}$ has been receiving especial attention. Several in vivo and in vitro studies have shown that lung tissue stretching upregulates NF- $\kappa \mathrm{B}(9,10)$. NF- $\kappa \mathrm{B}$ itself contains a DNA "shear stress" response element in its promoter region, and NF- $\mathrm{KB}$ protein binds to interleukin (IL)-6, IL-8, IL-1ß, and tumor necrosis factor- $\alpha$ (10).

Because of the complexity of the pulmonary structure, the possible mechanisms of mechanical stimulation and the potential cellular responses may vary extensively. There are a variety of cell types and physical forces to which cells are exposed. Furthermore, current evidence indicates that, in many cases, different types of stimuli use the same signaling pathways to coordinate the cell activity.

\section{Mechanically activated ion channel pathway}

Calcium is one of the most common molecules that mediate the intracellular signaling initiated by mechanical stress. Mechanical stretch increases $\mathrm{Ca}^{2+}$ influx, via a mechanosensitive cation channel that might be inhibited by both gadolinium (a nonselective inhibitor of stretch-activated ion channels) and verapamil (a blocker of $\mathrm{Ca}^{2+}$ chan-

Figure 1. Mechanically activated ion channel pathway. Stretch induces $\mathrm{Ca}^{2+}$ influx via a stretch-activated ion channel. Mechanical stretch also activates protein tyrosine kinases (PTK) that activates phospholipase $\mathrm{C}-\gamma$ (PLC- $\gamma$ ) via its tyrosine phosphorylation. PLC- $\gamma$ mediates the hydrolysis of phosphatidylinositol 4,5-bisphosphate $\left(\mathrm{PIP}_{2}\right)$ to produce inositol 1,4,5-trisphosphate $\left(\mathrm{IP}_{3}\right)$ and diacylglycerol (DAG). IP 3 mobilizes $\mathrm{Ca}^{2+}$ from intracellular storage sites. DAG in the presence of intracellular and extracellular $\mathrm{Ca}^{2+}$ activates protein $\mathrm{ki}-$ nase $C$ (PKC). PKC and other signals may activate transcriptional factors (c-fos) that bind to special response elements, such as stretch response elements (SRE), shear stress response elements (SSRE) and shear 12-O-tetradecanoylphorbol 13-acetate (TPA)-responsive element (TRE), boosting gene expression. nels) $(11,12)$. This stretch-induced change in $\mathrm{Ca}^{2+}$ homeostasis has been demonstrated in cultured pulmonary arterial smooth muscle cells (11), arterial endothelial cells (13), airway epithelial cells $(14,15)$, and fetal rat lung cells (12). Mechanical stretch also commandeers protein tyrosine kinases that activates phospholipase $\mathrm{C}-\gamma$ via its tyrosine phosphorylation. Phospholipase C- $\gamma$ mediates the hydrolysis of phosphatidylinositol 4,5-bisphosphate to produce inositol 1,4,5-trisphosphate and diacylglycerol. Inositol 1,4,5-trisphosphate mobilizes $\mathrm{Ca}^{2+}$ from intracellular storage. Diacylglycerol activates protein kinase $\mathrm{C}$ (PKC) in the presence of intracellular and extracellular $\mathrm{Ca}^{2+}$. PKC and other signals may activate transcriptional factors (c$f o s$ ) that bind to special response elements, such as stretch response elements (SRE), shear stress response elements (16) and 12O-tetradecanoylphorbol 13-acetate (TPA)responsive elements (TRE) (17), increasing gene expression (Figure 1). A 6-bp element

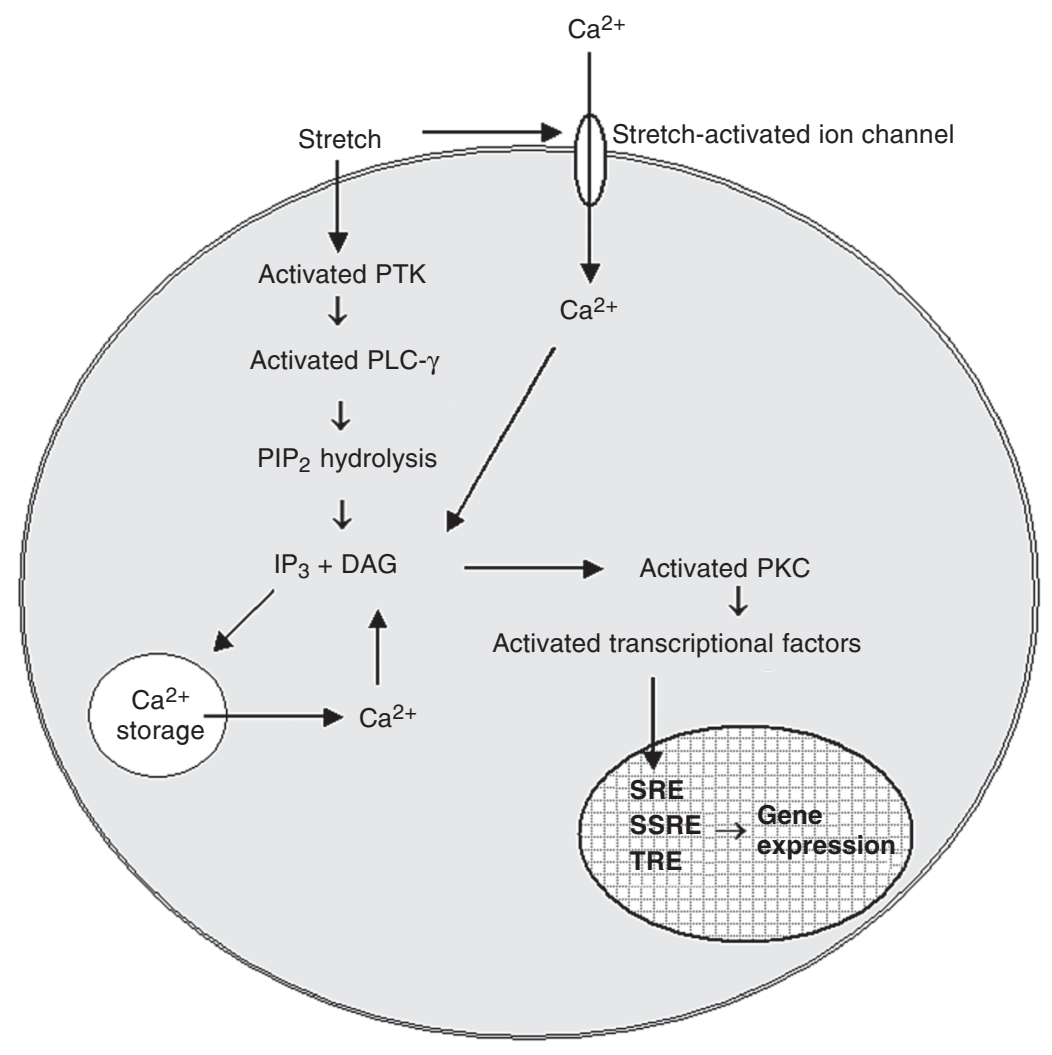


sensitive to various types of mechanical forces constitutes the shear stress response elements 'core'. The shear TRE, a divergent phorbol ester tissue-responsive element, can transduce mechanical signals to transcriptional events.

\section{Plasma membrane stress disruption pathway}

Plasma membrane disruption has been demonstrated by a number of methods, including laser confocal microscopy, electron microscopy, and uptake of high-molecular weight fluorescent dextran (18-20). The maintenance of plasma membrane integrity undoubtedly plays an important role in intracellular signaling pathways. Structural damage to cells leads to elevation in intracellular free $\mathrm{Ca}^{2+}$ concentrations caused by the influx of extracellular $\mathrm{Ca}^{2+}$ and the release of intracellular $\mathrm{Ca}^{2+}$ stores (21). Changes in $\mathrm{Ca}^{2+}$ homeostasis can affect signaling pathways and induce PKC activation. Traumatic breaks in the plasma membrane in response to mechanical stress (22) and changes in $\mathrm{Ca}^{2+}$ concentration (23) can induce an increase in c-fos expression. Plasma membrane stress disruption also induces the translocation and activation of NF- $\mathrm{KB}$ into the nucleus (22). PKC, activated NF- $\kappa B$, and cfos can induce the transcription of early response genes and bind to SRE to activate gene transcription (4).

\section{Matrix-integrin-cytoskeleton pathway}

Cells are attached to neighboring cells and to the ECM via transmembrane receptors of the cadherin and integrin families, respectively. On the cytoplasmic surface of the cell membrane, these receptors are coupled, either directly or indirectly, to a large number of proteins named cytoskeletal plaque proteins and, as a group, they form the focal adhesion complex (FAC). This complex provides a structural connection to trans- mit signals from ECM to cells (24). The tensegrity model proposed by Ingber (25) predicts that cells are hard-wired to respond immediately to mechanical stresses transmitted over cell surface receptors that physically couple the cytoskeleton to the ECM (e.g., integrins). The FAC serves as a macromolecular scaffold, which mechanically couples the cytoplasmic portion of integrins to the actin cytoskeleton. The FAC contains various types of molecules, including those associated with actin (e.g., vinculin, talin, paxilin, and $\alpha$-actin), focal adhesion kinase, kinases from the Src family, oncogene products, signaling molecules (e.g., tyrosine and serine protein kinases, and inositol lipid kinases), and some growth factor receptors. These molecules represent key candidates for transforming mechanical stimuli into biochemical signals. Cell stretch increases total protein tyrosine kinase activity and induces an association of the activated signaling intermediate pp $60^{\mathrm{src}}$ with the cytoskeleton (26). Mechanical stimulation may also directly alter the activity of receptor tyrosine kinases, such as Flk-1, thereby changing the association of integrins with Shc, activating Ras and downstream extracellular signalregulated protein kinase and c-Jun aminoterminal kinase pathways, which in turn lead to transcriptional activation of AP-1-TREmediated gene expression (27). A series of unidentified pathways activate subgroups of the mitogen-activating protein kinases [p38 kinase, stress-activated protein kinase, cJun amino-terminal kinase, and extracellular signal-regulated protein kinase 1/2] (28), and transcription factors such as early growth response-1 and specificity protein-1 (29). Subsequently, this diversity of molecules may activate NF- $\mathrm{\kappa B}$ and/or gene transcription through other mechanisms. Members of the integrin family can also regulate the action of NF- $\mathrm{KB}$ through activation of an inhibitor of NF- $\mathrm{KB}$ kinase. This in turn would mediate the release of NF- $\mathrm{KB}$ from an inhibitor of NF- $\mathrm{KB}$ by phosphorylation, and the 
subsequent translocation of NF- $\mathrm{KB}$ to the nucleus. Activation of members of the mitogen-activating protein kinase family and NF$\kappa \mathrm{B}$ can induce transcription of early response genes and bind to SRE to activate transcription (Figure 2) (4).

The elements of the cytoskeleton can be reorganized to increase the efficiency of transmitting signals from the ECM into the cell interior. The pulling of integrins by micropipettes reoriented cytoskeleton filaments, distorted nuclei, and redistributed nucleoli along the axis of the applied tension (30). Mechanical stress-induced changes in the cytoskeleton may alter the function of the structural molecules that make up the cytoskeleton and nucleus, including some critical regulatory proteins (31). Changing structural arrangements within the cytoskeleton and nuclear matrix may expose or obscure internal molecular binding sites, release

Figure 2. ECM-integrin-cytoskeleton pathway. Integrins maintain a close relationship with extracellular matrix (ECM), and actin-associated molecules (e.g., vinculin, talin, paxilin, and $\alpha$-actin), focal adhesion kinase (FAK), kinases from the Src family, oncogene products, signaling molecules (e.g., tyrosine and serine protein kinases, and inositol lipid kinases), and some growth factor receptors. Mechanical forces may alter the activity of receptor tyrosine kinases (Flk-1), changing the association of integrins with Shc, activating Ras and downstream extracellular signal-regulated protein kinase (ERK) and c-Jun amino-terminal kinase (JNK) pathways, which, in turn, lead to gene expression mediated by $12-0$-tetradecanoylphorbol 13-acetate (TPA)responsive elements (TRE). Mitogen-activating protein kinases (MAPK), p38 kinase, stress-activated protein kinase (SAPK), JNK, and transcription factors [early growth response (Egr)-1, specificity protein (SP)-1] are activated through a series of unidentified pathways. Subsequently, this variety of molecules may activate nuclear factor (NF)- $\mathrm{KB}$ and/or gene expression through other mechanisms. Members of the integrin family can also regulate the action of NF- $\mathrm{KB}$ by means of the activation of an inhibitor of NF-KB kinase (IKK) that mediates the release of NF-KB from the inhibitor of NF$\kappa B(I \kappa B)$, and the subsequent translocation of NF- $\kappa B$ to the nucleus. Activation of members of the MAPK family and NF-KB can induce transcription of early response genes and bind to stretch response elements (SRE) to activate transcription. mechanical constraints for molecular remodeling, or change the porosity of the network (31). This ECM-integrin-cytoskeleton interconnectedness could be very important for cells adapting to changes in their external environment.

\section{Cell-cell interaction}

Mechanical force-initiated signals need to be transmitted by intercellular communication. Mechanically force-induced intercellular signaling may involve autocrine, paracrine, juxtacrine, and cell-matrix interactions. Cells commonly use cytokines, growth factors, and other small soluble factors for communication. Cells can also transmit messages directly to one another by cellular junction or by their reciprocal interaction.

\section{Soluble factors}

Autocrine and paracrine mechanisms of cell-cell interaction are important for mechanical-force initiated signaling. There is evidence of hormone production by lung

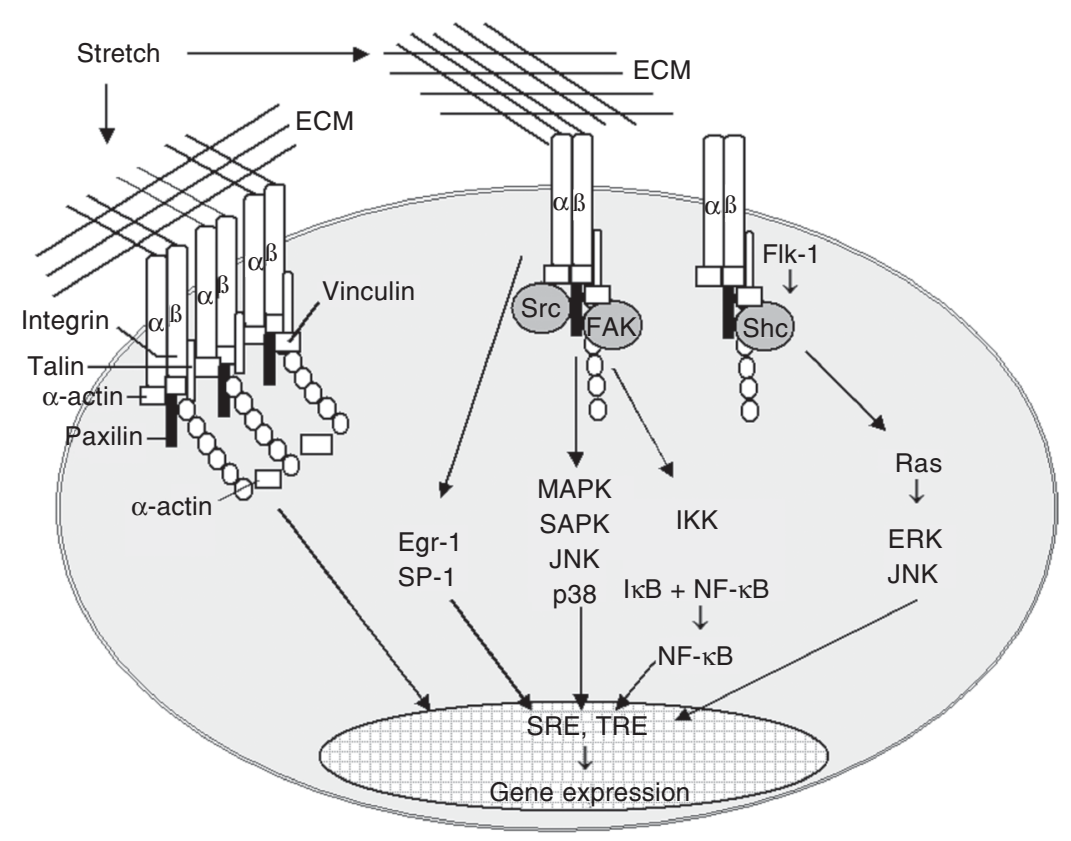


cells under mechanical stimulation. Mechanical stretch applied to cultured fetal lung epithelial cells stimulates the expression and production of a differentiation factor, parathyroid hormone-related peptide (PTHrP). Torday et al. (32) also observed an increased responsiveness of fetal lung fibroblasts to PTHrP. PTHrP released by type II cells specifically binds to its receptor on contiguous fibroblasts, stimulating cAMP as a second messenger to induce specific functions of fetal lung fibroblasts. This paracrine mechanism is putatively involved in augmenting glucocorticoid binding, increasing metabolic activities (such as lipoprotein lipase elaboration and triglyceride uptake), and stimulating production of cytokines (such as IL-6 and IL-11). These cytokine molecules can act as intercellular mediators, thereby increasing the synthesis of surfactant phospholipids and surfactant proteins from alveolar epithelial cells.

Growth factors constitute other commonly used soluble factors for intercellular communication. The strain-induced growthpromoting effect on fetal lung cells appears to be mediated by an increased production of endogenous growth factors. One of these growth factors has been identified as platelet-derived growth factor (PDGF)-B (33). Mechanical strain increases both gene and protein expression of PDGF-B and its receptor. Additionally, the blockade of the receptor with a protein tyrosine kinase inhibitor or with antisense PDGF-B oligonucleotides abolishes the strain-induced stimulatory effect on fetal lung cell proliferation (33). Further evidence for a strain-induced growthpromoting effect is the reduction of insulinlike growth factor gene expression observed by abolition of fetal lung breathing movements (34) and changes in fetal sheep lung volume owing to either tracheal obstruction or liquid drainage (35). These findings agree with fetal breathing movements controlling fetal lung growth via activation of growth factor expression.

\section{Intercellular junctions}

Tight junction barrier formation and gap junctional communication represent two functions directly attributable to cell-cell contact sites. Epithelial and endothelial tight junctions constitute critical elements of the permeability barrier required to maintain discrete compartments in the lung. On the other hand, gap junctions enable a tissue to act as a cohesive unit by permitting metabolic coupling and enabling the direct transmission of small cytosolic signaling molecules from one cell to another. Secondary messengers are probably transmitted across epithelial cell gap junctions and perhaps between different cell types (36). Additionally, the intracellular cytoskeleton interconnects neighboring cells through focal adhesion complexes in specialized junctional complexes (7). Tight and gap junctions do not act individually since other junctional elements, such as adherens junctions and desmosomes, help to regulate barrier function and intercellular communication (37). Intercellular adhesions in the alveoli transmit force by connecting epithelial cells into a sheet with the help of intermediate filaments. Adherens junctions probably act as mechanosensories. The mechanical stimulation of $\mathrm{n}$-cadherin in intercellular adherens junctions in fibroblasts causes gadolinium-sensitive calcium influx and induces actin polymerization at the sites where force was applied (38). Additionally, the expression of connexin proteins, the constituents of gap junctions in rat type- 2 cells, is modulated by the matrix protein fibronectin, abundant in the airspace after alveolar injury (39).

\section{Cell-matrix interaction}

The importance of cell-ECM interactions was demonstrated by stretching cells cultured on different ECM substrata (40). ECM modifies the ability of the cell to adhere to a surface and influences cell shape. For ex- 
ample, the contact with various ECM proteins modulates the ability of a mechanical signal to alter type I procollagen gene expression (40). Strained fibroblasts cultured on laminin or elastin, but not on fibronectin, expressed type I procollagen. These three ECM molecules form some of the main support structures in the lung that would represent load-bearing elements resistant to tissue stretch.

Glycosaminoglycans (GAGs) also participate in cell-matrix interactions by effectively modulating the cellular phenotype via high-affinity binding sites. GAGs interact with other ECM proteins influencing the macromolecular organization and also regulate collagen fibrillogenesis. GAGs modulate the steady-state levels of mRNA expression: 1) in a cell type-specific manner, and 2) with different GAGs selectively modulating cell-matrix interactions (41).

As previously reported, specific focal adhesion on the cell surface allows the mechanical stretch generated in the system to be transduced to the cytoskeletal network. Thus, the cell constitutes an integrated system in terms of mechanical force transduction. A change in the cytoskeletal architecture is transmitted to the nuclear matrix, ultimately allowing the expression of a subset of gene products (31).

\section{Stretch-induced production of inflammatory mediators}

Recently, considerable attention has been focused on the release of inflammatory mediators from lung cells exposed to mechanical forces. In this context, several groups have employed cell culture models to examine the stretch-induced inflammatory response (42-46).

\section{Cytokine release}

Human macrophages under strain induced by a $12 \%$ increase in surface area at 20 cycles/min produce IL-8 via NF-אB (42). However, the same stretch regimen applied to human lung epithelial A549 cells did not elevate IL-8 content. On the other hand, A549 lung epithelial cells submitted to a strain of $30 \%$ at a frequency of 20 or 40 cycles/min augmented IL-8 after 12-48 h (43). IL-8 content also rose when A549 epithelial cells were exposed to a $40 \%$ strain (46). Thus, the release of IL- 8 depends on the magnitude of cyclic strain on alveolar cells.

Additional in vitro studies emphasize the importance of the association of a subjacent inflammatory injury and a mechanical deformation to induce the release of cytokines. In this context, Tsuda and colleagues (44) observed that stretch alone did not affect IL8 production after $8 \mathrm{~h}$; however, in the presence of glass fibers or crocidolite asbestos, stretch significantly increases IL-8 production in cultured A549 cells. Similarly, mechanical stretch applied to primary cultured fetal rat lung cells increases mRNA levels of macrophage inflammatory protein-2 (the rodent equivalent of human IL-8) only after lipopolysaccharide (45).

\section{Prostaglandin synthesis}

The alteration of physical forces represents an important factor in lung inflammatory diseases. The synthesis of biologically active eicosanoids by lung cells contributes to the regulation of smooth muscle tone and of inflammatory responses. Prostaglandin synthesis in response to mechanical forces may vary with the type of cell and stimulus. For example, cyclic stretch down-regulates the synthesis of prostaglandins including PGE2, PGI2, and thromboxane A2 in cat and human airway epithelial cells (47). This inhibitory effect seems to result from the inactivation of cyclooxygenase. In contrast, shear stress increases the production of prostacyclin by lung endothelial cells (48) and mechanical strain induces a rapid release of prostacyclin by fetal rat lung cells (49). 


\section{Stretch-induced extracellular matrix expression}

The ECM transmits essential information to pulmonary cells, thereby regulating their proliferation, differentiation, and organization (50). The components of the ECM can be divided into four broad categories: collagen, non-collagenous glycoproteins (such as fibronectin and laminin), glycosaminoglycans and proteoglycans (PTGs), and elastic fibers $(48,51,52)$. Cells continuously remodel their microenvironment by changing the components and structure of the ECM $(52,53)$. Most cell types in lung tissue contribute to the dynamic changes in the ECM. Regulation of ECM dynamics is complicated, involving a balance between synthesis and deposition of ECM molecules as well as their degradation (54). A family of secreted proteases, matrix metalloproteinases, plays a role in ECM turnover $(54,55)$. Matrix metalloproteinase activity is regulated by a variety of mechanisms, including synthesis, secretion, and inhibition by stoichiometric complexing of tissue inhibitors of metalloproteinases to the activated enzymes (55).

Mechanical forces alter the gene expression and protein synthesis of several lung ECM molecules such as collagen, GAGs and PTGs. An intermittent mechanical strain may regulate gene and protein expression of lung ECM molecules in a different manner (56). Differences in the regional distribution of mechanical stress or in the extent of injury generate diverse patterns of matrix protein expression (57). Moreover, the increase in matrix accumulation seems to be mainly related to a higher ECM synthesis rather than to a less important activity of degradative enzymes (56).

Mechanical forces increase procollagen fiber expression (40,56-58), and the exact role of physical forces in type III procollagen expression has been recently elucidated. In this context, Garcia and colleagues (59) analyzed lung mechanical stretch induced by different levels of stress and strain and observed that there is a threshold stress above which lung cells express mRNA for type III procollagen. Furthermore, Farias and colleagues (58) showed that even a short period (40 s) of lung mechanical stretch $\left(40 \mathrm{cmH}_{2} \mathrm{O}\right.$ of continuous positive airway pressure) increases type III procollagen mRNA expression.

Intermittent mechanical strain simulating fetal breathing movements also induces the secretion of GAGs and PTGs. Mechanical strain appears mainly to affect the distal part of the secretory pathway, i.e., GAGs and PTGs trafficking from the trans-Golgi apparatus to the cell surface membrane. Strain-enhanced GAG release was partially blocked by BAPTA/AM (an intracellular calcium chelator) and completely abolished by gadolinium (a stretch-activated ion channel blocker). These results suggest that calcium influx, rather than calcium mobilization from intracellular stores, represents the most important trigger for mechanical strain-induced GAG exocytosis in fetal lung cells (60).

In recent years there has been a growing recognition that physical forces play an important role regarding pathophysiologic processes in human disease states. The present review describes how cells sense mechanical stimulation, transmit signals intra- and intercellularly, and regulate gene expression and protein synthesis. Experimental advances have significantly increased our understanding of the process of mechanotransduction in lung cells. However, there are some missing links along the intracellular pathways. Further investigation in this research field will facilitate our understanding of pulmonary physiology and pathophysiology at the cellular and molecular levels. In addition, the understanding of the mechanisms by which cells in the lung transduce forces generated by mechanical ventilation into biological signals is of key importance for reducing or eliminating the deleterious consequences of the ventilator. 


\section{References}

1. Wirtz HR, Dobbs LG. The effects of mechanical forces on lung functions. Respir Physiol 2000; 119: 1-17.

2. Chicurel ME, Chen CS, Ingber DE. Cellular control lies in the balance of forces. Curr Opin Cell Biol 1998; 10: 232-239.

3. Gattinoni L, Carlesso E, Cadringher P, Valenza F, Vagginelli F, Chiumello D. Physical and biological triggers of ventilator-induced lung injury and its prevention. Eur Respir J Supp/ 2003; 47: 15S25 S.

4. Dos Santos CC, Slutsky AS. Mechanisms of ventilators-induced lung injury: a perspective. J Appl Physiol 2000; 89: 1645-1655.

5. Young WC. Roark's Formulas for Stress and Strain. New York: McGraw-Hill Inc.; 1989.

6. Sackin H. Mechanosensitive channels. Annu Rev Physiol 1995; 57: 333-353.

7. Wang N, Butler JP, Ingber DE. Mechanotransduction across the cell surface and through the cytoskeleton. Science 1993; 260: 11241127.

8. Ingber DE. Tensegrity: the architectural basis of cellular mechanotransduction. Annu Rev Physiol 1997; 59: 575-599.

9. Komuro I, Katoh Y, Kaida T, Shibazaki Y, Kurabayashi M, Hoh E, et al. Mechanical loading stimulates cell hypertrophy and specific gene expression in cultured rat cardiac myocytes. Possible role of protein kinase C activation. J Biol Chem 1991; 266: 1265-1268.

10. Schwartz MD, Moore EE, Moore FA, Shenkar R, Moine P, Haenel $\mathrm{JB}$, et al. Nuclear factor-kappa B is activated in alveolar macrophages from patients with acute respiratory distress syndrome. Crit Care Med 1996; 24: 1285-1292.

11. Blackwell TS, Christman JW. The role of nuclear factor-kappa B in cytokine gene regulation. Am J Respir Cell Mol Biol 1997; 17: 3-9.

12. Bialecki RA, Kulik TJ, Colucci WS. Stretching increases calcium influx and efflux in cultured pulmonary arterial smooth muscle cells. Am J Physiol 1992; 263: L602-L606.

13. Liu M, Xu J, Tanswell AK, Post M. Inhibition of mechanical straininduced fetal rat lung cell proliferation by gadolinium, a stretchactivated channel blocker. J Cell Physiol 1994; 161: 501-507.

14. Winston FK, Thibault LE, Macarak EJ. An analysis of the timedependent changes in intracellular calcium concentration in endothelial cells in culture induced by mechanical stimulation. $J$ Biomech Eng 1993; 115: 160-168.

15. Boitano S, Sanderson MJ, Dirksen ER. A role for $\mathrm{Ca}\left({ }^{2+}\right)$-conducting ion channels in mechanically-induced signal transduction of airway epithelial cells. J Cell Sci 1994; 107: 3037-3044.

16. Resnick N, Collins T, Atkinson W, Bonthron DT, Dewey Jr CF, Gimbron Jr MA. Platelet-derived growth factor B chain promoter contains a cis-acting fluid shear-stress-responsive element. Proc Natl Acad Sci U S A 1993; 90: 7908.

17. Shyy JY, Lin MC, Han J, Lu Y, Petrime M, Chien S. The cis-acting phorbol ester "12-O-tetradecanoylphorbol 13-acetate"-responsive element is involved in shear stress-induced monocyte chemotactic protein 1 gene expression. Proc Natl Acad Sci U S A 1995; 92: 8069-8073.

18. McNeil PL, Steinhardt RA. Loss, restoration, and maintenance of plasma membrane integrity. J Cell Biol 1997; 137: 1-4.

19. Terasaki M, Miyake K, McNeil PL. Large plasma membrane disruptions are rapidly resealed by $\mathrm{Ca}^{2+}$-dependent vesicle-vesicle fusion events. J Cell Biol 1997; 139: 63-74.

20. West JB. Pulmonary capillary stress failure. J Appl Physiol 2000; 89: 2483-2489.
21. Hinman LE, Beilman GJ, Groehler KE, Sammak PJ. Wound-induced calcium waves in alveolar type II cells. Am J Physiol 1997; 273: L1242-L1248.

22. Grembowicz KP, Sprague D, McNeil PL. Temporary disruption of the plasma membrane is required for $\mathrm{c}$-fos expression in response to mechanical stress. Mol Biol Cell 1999; 10: 1247-1257.

23. Bajpai $A$, Andrews GK, Ebner KE. Induction of c-fos mRNA in rat lymphoma Nb-2 cells. Biochem Biophys Res Commun 1989; 165: 1359-1363.

24. Juliano RL, Haskill S. Signal transduction from the extracellular matrix. J Cell Biol 1993; 120: 577-585.

25. Ingber DE. The riddle of morphogenesis: a question of solution chemistry or molecular cell engineering? Cell 1993; 75: 1249-1252.

26. Liu M, Qin Y, Liu J, Tanswell AK, Post M. Mechanical strain induces pp60src activation and translocation to cytoskeleton in fetal rat lung cells. J Biol Chem 1996; 271: 7066-7071.

27. Chen KD, Li YS, Kim M, Li S, Yuan S, Chien S, et al. Mechanotransduction in response to shear stress. Roles of receptor tyrosine kinases, integrins, and Shc. J Biol Chem 1999; 274: 18393-18400.

28. Quinn D, Tager A, Joseph PM, Bonventre JV, Force T, Hales CA. Stretch-induced mitogen-activated protein kinase activation and interleukin-8 production in type II alveolar cells. Chest 1999; 116: 89S90S.

29. Silverman ES, Khachigian LM, Lindner V, Williams AJ, Collins T. Inducible PDGF A-chain transcription in smooth muscle cells is mediated by Egr-1 displacement of Sp1 and Sp3. Am J Physiol 1997; 273: H1415-H1426.

30. Maniotis AJ, Chen CS, Ingber DE. Demonstration of mechanical connections between integrins, cytoskeletal filaments, and nucleoplasm that stabilize nuclear structure. Proc Natl Acad Sci U S A 1997; 94: 849-854.

31. Ingber DE. Integrins as mechanochemical transducers. Curr Opin Cell Biol 1991; 3: 841-848.

32. Torday JS, Liu M, Liu J, Caniggia I, Post M. Mesenchymal determination of mechanical strain-induced fetal lung cell proliferation. $A m \mathrm{~J}$ Physiol 1998; 275: L545-L550.

33. Liu M, Liu J, Buch S, Tanswell AK, Post M. Antisense oligonucleotides for PDGF-B and its receptor inhibit mechanical strain-induced fetal lung cell growth. Am J Physiol 1995; 269: L178-L184.

34. Harding R, Hooper SB, Han VK. Abolition of fetal breathing movements by spinal cord transection leads to reductions in fetal lung liquid volume, lung growth, and IGF-II gene expression. Pediatr Res 1993; 34: 148-153.

35. Hooper SB, Han VK, Harding R. Changes in lung expansion alter pulmonary DNA synthesis and IGF-II gene expression in fetal sheep. Am J Physiol 1993; 265: L403-L409.

36. Adamson IY, Young L, King GM. Reciprocal epithelial: fibroblast interactions in the control of fetal and adult rat lung cells in culture. Exp Lung Res 1991; 17: 821-835.

37. Boitano S, Safdar Z, Welsh DG, Bhattacharya J, Koval M. Cell-cell interactions in regulating lung function. Am J Physiol 2004; 287: L455-L459.

38. Ko KS, Arora PD, McCulloch CA. Cadherins mediate intercellular mechanical signaling in fibroblasts by activation of stretch-sensitive calcium-permeable channels. J Biol Chem 2001; 276: 35967-35977.

39. Guo Y, Martinez-Williams C, Yellowley CE, Donahue HJ, Rannels DE. Connexin expression by alveolar epithelial cells is regulated by extracellular matrix. Am J Physiol 2001; 280: L191-L202. 
40. Breen EC. Mechanical strain increases type I collagen expression in pulmonary fibroblasts in vitro. J Appl Physiol 2000; 88: 203-209.

41. Schaefer T, Roux M, Stuhlsatz HW, Herken R, Coulomb B, Krieg T, et al. Glycosaminoglycans modulate cell-matrix interactions of human fibroblasts and endothelial cells in vitro. J Cell Sci 1996; 109 (Part 2): 479-488.

42. Pugin J, Dunn I, Jolliet P, Tassaux D, Magnenat JL, Nicod LP, et al. Activation of human macrophages by mechanical ventilation in vitro. Am J Physiol 1998; 275: L1040-L1050.

43. Vlahakis NE, Schroeder MA, Limper AH, Hubmayr RD. Stretch induces cytokine release by alveolar epithelial cells in vitro. Am J Physiol 1999; 277: L167-L173.

44. Tsuda A, Stringer BK, Mijailovich SM, Rogers RA, Hamada K, Gray $\mathrm{ML}$. Alveolar cell stretching in the presence of fibrous particles induces interleukin-8 responses. Am J Respir Cell Mol Biol 1999; 21: 455-462.

45. Mourgeon E, Isowa N, Keshavjee S, Zhang X, Slutsky AS, Liu M. Mechanical stretch stimulates macrophage inflammatory protein-2 secretion from fetal rat lung cells. Am J Physiol Lung Cell Mol Physiol 2000; 279: L699-L706.

46. Yamamoto $H$, Teramoto $H$, Uetani K, Igawa K, Shimizu E. Stretch induces a growth factor in alveolar cells via protein kinase. Respir Physiol 2001; 127: 105-111.

47. Savla U, Sporn PH, Waters CM. Cyclic stretch of airway epithelium inhibits prostanoid synthesis. Am J Physiol 1997; 273: L1013-L1019.

48. Reeves JT, van Grodelle A, Voelkel NF, Walker B, Lindenfeld J, Worthen S, et al. Prostacyclin production and lung endothelial cell shear stress. Prog Clin Biol Res 1983; 136: 125-131.

49. Skinner SJ, Somervell CE, Olson DM. The effects of mechanical stretching on fetal rat lung cell prostacyclin production. Prostaglandins 1992; 43: 413-433.

50. Guzowski DE, Blau H, Bienkowski RS. Extracellular matrix in developing lung. In: Scarpelli E (Editor), Pulmonary Physiology of Fetus, Child and Adolescent. Philadelphia: Lea \& Febiger; 1989.

51. Garcia CSNB, Rocco PRM, Zin WA. Understanding the mechanism of ventilator-induced lung injury. In: Gullo A, Berlot G (Editors), Perioperative and Critical Care Medicine. Milan: Springer; 2005.

52. Rocco PR, Negri EM, Kurtz PM, Vasconcellos FP, Silva GH, Capelozzi VL, et al. Lung tissue mechanics and extracellular matrix remodeling in acute lung injury. Am J Respir Crit Care Med 2001; 164: 1067-1071.

53. Menezes SL, Bozza PT, Neto HC, Laranjeira AP, Negri EM, Capelozzi VL, et al. Pulmonary and extrapulmonary acute lung injury: inflammatory and ultrastructural analyses. $J$ Appl Physiol 2005; 98: 1777-1783.

54. Santos FB, Nagato LK, Boechem NM, Negri EM, Guimaraes A, Capelozzi VL, et al. Time course of lung parenchyma remodeling in pulmonary and extrapulmonary acute lung injury. J Appl Physiol 2006; 100: 98-106.

55. Murphy G, Docherty AJ. The matrix metalloproteinases and their inhibitors. Am J Respir Cell Mol Biol 1992; 7: 120-125.

56. Xu J, Liu M, Post M. Differential regulation of extracellular matrix molecules by mechanical strain of fetal lung cells. Am J Physiol 1999; 276: L728-L735.

57. Parker JC, Breen EC, West JB. High vascular and airway pressures increase interstitial protein mRNA expression in isolated rat lungs. $J$ Appl Physiol 1997; 83: 1697-1705.

58. Farias LL, Faffe DS, Xisto DG, Santana MC, Lassance R, Prota LF, et al. Positive end-expiratory pressure prevents lung mechanical stress caused by recruitment/derecruitment. J Appl Physiol 2005; 98: 53-61.

59. Garcia CS, Rocco PR, Facchinetti LD, Lassance RM, Caruso P, Deheinzelin D, et al. What increases type III procollagen mRNA levels in lung tissue: stress induced by changes in force or amplitude? Respir Physiol Neurobiol 2004; 144: 59-70.

60. Xu J, Liu M, Liu J, Caniggia I, Post M. Mechanical strain induces constitutive and regulated secretion of glycosaminoglycans and proteoglycans in fetal lung cells. J Cell Sci 1996; 109 (Part 6): 16051613. 